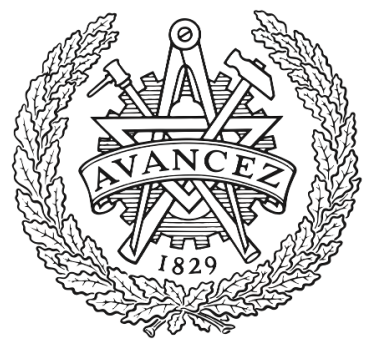

CHALMERS

UNIVERSITY OF TECHNOLOGY

\title{
Combining in Silico Tools with Multicriteria Analysis for Alternatives Assessment of Hazardous Chemicals: A Case Study of Decabromodiphenyl
}

Downloaded from: https://research.chalmers.se, 2023-04-26 13:59 UTC

Citation for the original published paper (version of record):

Zheng, Z., Peters, G., Arp, H. et al (2019). Combining in Silico Tools with Multicriteria Analysis for Alternatives Assessment of Hazardous

Chemicals: A Case Study of Decabromodiphenyl Ether Alternatives. Environmental Science \& Technology, 53(11): 6341-6351. http://dx.doi.org/10.1021/acs.est.8b07163

N.B. When citing this work, cite the original published paper. 


\title{
Combining in Silico Tools with Multicriteria Analysis for Alternatives Assessment of Hazardous Chemicals: A Case Study of Decabromodiphenyl Ether Alternatives
}

\author{
Ziye Zheng, ${ }^{\dagger}$ Gregory M. Peters, ${ }^{\ddagger}, \S$ Hans Peter H. Arp, ${ }^{\|, \perp}$ and Patrik L. Andersson ${ }^{*}, \dagger$ \\ ${ }^{\dagger}$ Department of Chemistry, Umeå University, SE-901 87 Umeå, Sweden

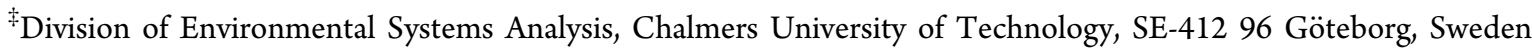 \\ ${ }^{\S}$ School of Civil and Environmental Engineering, University of New South Wales, AU-2052 Sydney, Australia \\ "Department of Environmental Engineering, Norwegian Geotechnical Institute, Ullevaal Stadion, NO-0806 Oslo, Norway \\ ${ }^{\perp}$ Department of Chemistry, Norwegian University of Science and Technology (NTNU), NO-7491 Trondheim, Norway
}

Supporting Information

\begin{abstract}
Alternatives assessment is applied for minimizing the risk of unintentionally replacing a hazardous chemical with another hazardous chemical. Central challenges are the diversity of properties to consider and the lack of high-quality experimental data. To address this, a novel alternatives assessment procedure was developed based on in silico data and multicriteria decision analysis (MCDA) methods. As a case study, 16 alternatives to the flame retardant decabromodiphenyl ether were considered. The hazard properties included persistence $(\mathrm{P})$, bioaccumulation potential (B), toxicities $(\mathrm{T})$, and mobility in water $(\mathrm{M})$. Databases were consulted and 2866 experimental data points were collected for the target chemicals; however, these were mostly replicate data points for some hazard criteria for a subset of alternatives. Therefore, in silico data and three MCDA strategies were tested including heat mapping, multiattribute utility theory (MAUT), and Elimination Et Choix Traduisant la REalité (ELECTRE III). The heat map clearly showed that none of the target chemicals are hazard-free, whereas MAUT and ELECTRE III agreed on ranking the "least worst" choices. This study identified several challenges and the complexity in the alternatives assessment processes motivating more case studies combining in silico and MCDA approaches.
\end{abstract}

\section{INTRODUCTION}

With increasingly stringent chemical regulations ${ }^{1,2}$ as well as pressure from the public regarding the safe use of chemicals, tools to facilitate the identification of potentially hazardous substances prior to use are needed. These tools would facilitate responsible management of such hazardous substances as well as help identify safer alternatives. However, the process of alternatives assessment is not trivial. There are several examples of regrettable substitution where one hazardous chemical has been substituted by another problematic chemical, such as the substitution of bisphenol A with other bisphenols (e.g., bisphenol S, bisphenol AF, and fluorene-9bisphenol, etc.) of which some have been identified as endocrine disruptors. ${ }^{3,4}$ Another is the choice of $n$-hexane to replace chlorinated solvents for the automotive cleaning industry; this was later reported to be neurotoxic. ${ }^{5} \mathrm{~N}$-vinyl formamide, which requires toxic hydrogen cyanide during synthesis, was chosen as a substitute for the neurotoxic acrylamide in manufacturing polymers for water treatment. ${ }^{6}$ Alternatives assessments of chemicals are typically performed using a broad, established framework such as the Design for the Environment (DfE) Program, ${ }^{7}$ Cleaner technologies substitutes assessment (CTSA), ${ }^{8}$ BizNGO with GreenScreen, ${ }^{9}$ and Interstate Chemicals Clearinghouse (IC2), ${ }^{10}$ that considers substances with the same or similar uses, considering both environmental and human health aspects. ${ }^{11-14} \mathrm{~A}$ complete alternatives assessment framework would evaluate not only hazard and exposure parameters, but also life-cycle impacts, technical performance, and costs. ${ }^{15}$ In addition, a decisionaiding component is needed to integrate and balance all these factors, so that all aspects including stakeholder perspectives are considered. Since the 1990s, several alternatives assessment frameworks have been developed and implemented. ${ }^{15}$ Regarding the hazard assessment component, almost all frameworks take human health and ecological effects into consideration by including chemical persistency $(\mathrm{P})$, bioaccumulation potential $(\mathrm{B})$, and toxicity $(\mathrm{T})$ properties. $^{15}$

Received: December 19, 2018

Revised: May 10, 2019

Accepted: May 13, 2019

Published: May 13, 2019 


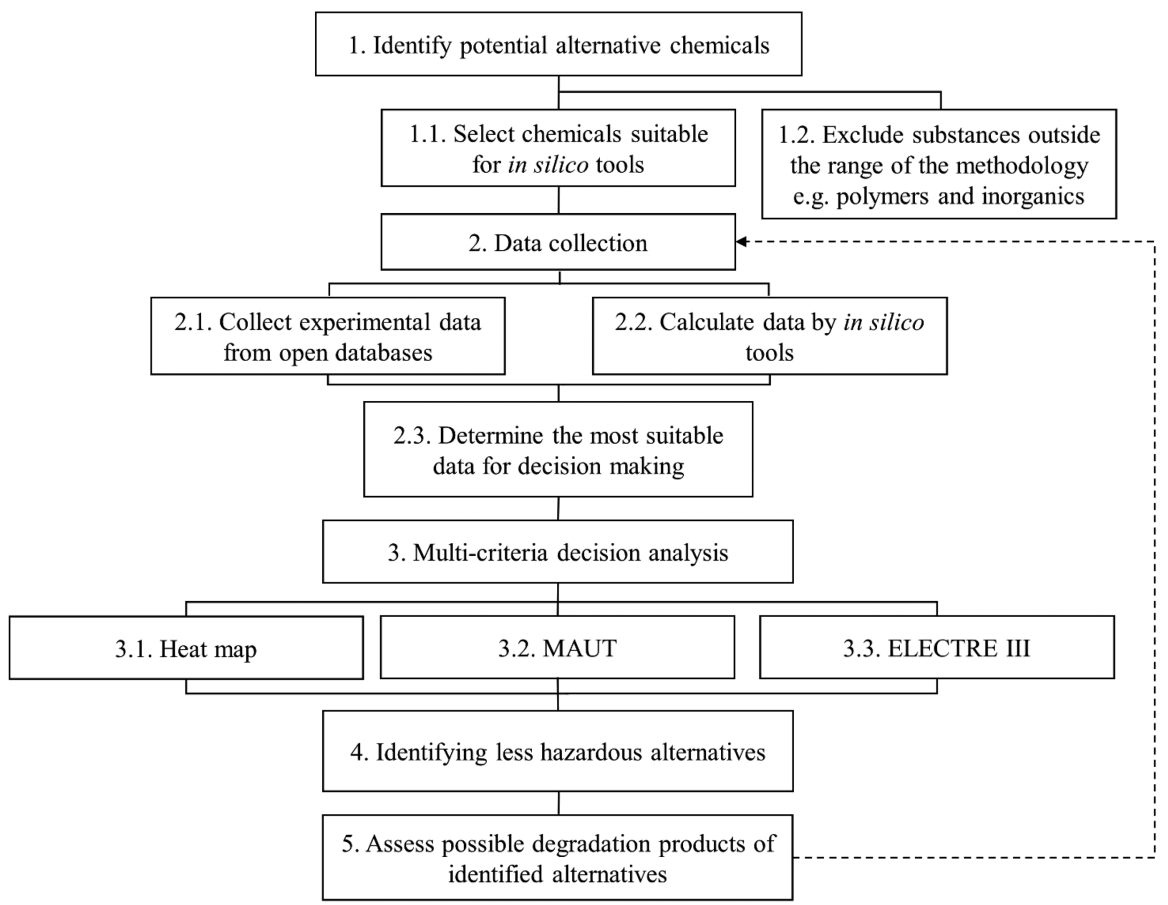

Figure 1. Work flow of the developed alternatives assessment procedure.

More recently, arguments have been presented that chemical mobility in water (M) is an important property. Chemical risk assessment used to focus more on nonpolar compounds in particular, due to their bioaccumulation potential, while polar organic chemicals sorb less to organic matter in soils and sediment, and therefore, they are more mobile in aquatic environments. Compounds that are persistent and mobile can reach aquatic biota in surface waters, and even reach drinking water resources, potentially leading to chronic human exposure. Therefore, a PMT assessment should be considered in addition to the widely used PBT assessment. ${ }^{16-20}$

When estimating chemical hazards, experimental data are often unavailable, especially if alternatives are newly introduced on the market and the production volumes are low. Thus, alternatives assessment processes are often hampered by large data gaps. ${ }^{6}$ To fill these gaps, in silico tools, for example, quantitative structure-activity relationship (QSAR) models or "read-across" approaches could be used. A QSAR is a regression model where chemical descriptors reflecting key physicochemical and structural features of chemicals are correlated with a biological or toxicological activity, which can be considered a subset of read-across approaches. Readacross also refers to quantitative and qualitative methods but is more general because a "read-across" may rely on relatively sparse data which do not support complicated predictive modeling. ${ }^{21}$ In silico tools have the advantage of providing a large amount of data with much lower cost and time requirements. Uncertainties in in silico data are generally higher compared with experimental data; however, such data are useful especially at the screening level, if certain model conditions are fulfilled including assessment of the applicability domain. ${ }^{2,22,23}$

Alternatives assessment frameworks demand the comparison of diverse sets of criteria; but do not necessarily provide an approach for this. For decision making based on multiple and conflicting criteria, Multicriteria Decision Analysis (MCDA) methods provide an option, drawn from operations research. ${ }^{24}$
MCDA is commonly used in the business sector, but it has also proved itself useful for several environmental management applications. $^{25-31}$ The two major kinds of MCDA methods are synthesizing criterion methods and synthesizing preference relational systems. ${ }^{32}$ Synthesizing criterion methods include those based on multiattribute utility theory (MAUT), ${ }^{33}$ which requires all criteria to be converted into comparable scales, and a trade-off weighting factor representing the relative significance of each criterion to be assigned in order to permit aggregation. Synthesizing preference relational systems, such as the Elimination Et Choix Traduisant la REalité (ELECTRE III) method, ${ }^{34}$ compare the performance of pairs of alternatives with respect to each criterion, and build a "credibility matrix" which presents the extent to which an alternative outranks the other alternatives. Importance coefficients are used instead of trade-off weights.

In recent years, a number of brominated flame retardants (BFRs) have been replaced after being banned or restricted for certain applications. ${ }^{35,36}$ A review claimed that the adverse environmental and human health impacts caused by certain BFRs might even be greater than their fire safety benefits. ${ }^{37}$ One example is decabromodiphenyl ether (decaBDE) that has been used in different products and materials including electric equipment, electronics, vehicles, furniture, and textiles since 1970s, but was later found to be persistent in the environment, ${ }^{38}$ bioaccumulative, ${ }^{39}$ and to induce adverse effects on both human health and other species. ${ }^{2,40-43}$ DecaBDE has been banned in the EU since 2008 for use in electronic and electric applications ${ }^{44-46}$ and listed by the Stockholm Convention on Persistent Organic Pollutants (Annex A). ${ }^{47}$ In the U.S., both producers and importers announced in 2010 that they would voluntarily phase out decaBDE by the end of 2013. ${ }^{48}$ However, years after the phase-out, decaBDE has still been identified in recently purchased electronics. ${ }^{49}$

Some other BFRs have been used as alternatives to decaBDE, such as decabromodiphenyl ethane (DBDPE). However, this substance was later found to also be 
persistent, ${ }^{50-53}$ bioaccumulative, ${ }^{54-56}$ potentially toxic, ${ }^{36}$ and could arguably be considered another example of regrettable substitution. One large class of flame retardants widely used to replace BFRs is the organophosphorus flame retardants (OPFRs). Although some studies show that these OPFRs are generally safer than BFRs, ${ }^{36}$ many studies also point out that some OPFRs are persistent, have the potential for longrange transport, ${ }^{57}$ and can be neurotoxic. ${ }^{58,59}$

Herein, a new alternatives assessment procedure based on the combination of in silico approaches and MCDA is developed (Figure 1), using alternatives to decaBDE as a test case. A variety of human health and environmental hazards were in focus. This included the mobility hazard, which to our knowledge has never been used within alternatives assessments. The approach presented here is based on open source data and models, and aims at deriving a transparent tool for a first phase alternatives assessment, which evaluates the hazardous properties of chemicals.

\section{MATERIALS AND METHODS}

The developed alternatives assessment procedure is summarized in Figure 1. A thorough alternatives assessment should consider both the hazard of parent compounds and their possible transformation products. In this study, we focused on the parent compounds as the case chemicals and proceeded through the first three steps: alternative chemical identification; data collection; and multicriteria decision aiding.

Case Chemical Identification and Characterization. A set of potential alternatives to decaBDE was identified using literature sources ${ }^{60,61}$ and reports from the EU, ${ }^{45,46}$ United States Environmental Protection Agency (USEPA), ${ }^{54}$ and one from the U.S. National Research Council. ${ }^{6}$ A database was established with chemical names, CAS numbers, and molecular structures represented by simplified molecular input line entry specification (SMILES). Alternatives to decaBDE include a large range of chemicals, but here we focused on organic chemicals and avoided metals and polymers, due to the lack of data and in silico tools for these types of substances. Details on how chemicals were selected can be found in Section 1 of the Supporting Information (SI).

Data Collection. The variation among the chemical properties was studied using principal component analysis (PCA) and a set of 65 chemical descriptors. ${ }^{62}$ The descriptors were derived using the MOE software ${ }^{63}$ based on 2D structures. In addition, selected physicochemical properties were calculated by EPISUITE. ${ }^{64}$ The octanol-water partition coefficient was derived in EPISUITE and by two alternative models in VEGA. ${ }^{65}$

Experimental data were acquired using the OECD QSAR Toolbox, ${ }^{66}$ which contains five databases for physicochemical properties, 12 databases for environmental fate and transport parameters, six databases for ecotoxicity, and 39 databases for human toxicity data. Among these databases, the ECHA database of the REACH registration dossiers is one of the most important, being populated with experimental data and some modeling data on chemical properties and toxicity for substances registered under REACH as provided by registrants who manufacture or import the substance within the European Union. ${ }^{2}$ Registered experimental data was acquired directly from the ECHA Web site. ${ }^{67}$

The in silico-based data were derived using several open source software packages or platforms including EPISUITE, VEGA, TEST, ${ }^{68}$ and OECD QSAR Toolbox. ${ }^{66}$ Results from the USEPA organized Collaborative Estrogen Receptor Activity Prediction Project (CERAPP) ${ }^{69}$ and Collaborative Modeling Project for Androgen Receptor Activity (CoMPARA $)^{70,71}$ were also included. Six models on the OCHEM platform $^{72}$ were included. Details on the assessment criteria and in silico models are given in Table 1.

Table 1. In Silico Models Used for the Alternatives Assessment in This Study

\begin{tabular}{|c|c|c|c|c|}
\hline & aspects & $\begin{array}{l}\text { assessment } \\
\text { criteria }\end{array}$ & $\begin{array}{l}\text { number of } \\
\text { models }\end{array}$ & $\begin{array}{l}\text { software or } \\
\text { platforms }\end{array}$ \\
\hline \multirow[t]{5}{*}{$\mathrm{P}$} & & air half-life & 1 & $\begin{array}{l}\text { EPISUITE } \\
\text { (fugacity } \\
\text { model) }\end{array}$ \\
\hline & & water half-life & 1 & $\begin{array}{l}\text { EPISUITE } \\
\text { (fugacity } \\
\text { model) }\end{array}$ \\
\hline & & soil half-life & 1 & $\begin{array}{l}\text { EPISUITE } \\
\text { (fugacity } \\
\text { model) }\end{array}$ \\
\hline & & sediment half-life & 1 & $\begin{array}{l}\text { EPISUITE } \\
\text { (fugacity } \\
\text { model) }\end{array}$ \\
\hline & & biodegradation & 1 & $\begin{array}{l}\text { EPISUITE } \\
\quad \text { (Biowin 3) }\end{array}$ \\
\hline B & & $\mathrm{BCF}$ & 3 & $\begin{array}{l}\text { VEGA, } \\
\text { EPISUITE }\end{array}$ \\
\hline \multirow[t]{13}{*}{$\mathrm{T}$} & human toxicity & mutagenicity & 4 & VEGA \\
\hline & & carcinogenicity & 3 & VEGA \\
\hline & & $\begin{array}{l}\text { developmental } \\
\text { toxicity }\end{array}$ & 2 & VEGA \\
\hline & & estrogen binding & 5 & $\begin{array}{l}\text { VEGA, OCHEM, } \\
\text { CERAPP }\end{array}$ \\
\hline & & $\begin{array}{r}\text { androgen } \\
\text { binding }\end{array}$ & 4 & $\begin{array}{l}\text { OCHEM, } \\
\text { COMPARA }\end{array}$ \\
\hline & & $\begin{array}{l}\text { transthyretin } \\
\text { binding }\end{array}$ & 1 & OCHEM \\
\hline & & skin sensitization & 1 & VEGA \\
\hline & & skin irritation & 1 & $\begin{array}{l}\text { OECD QSAR } \\
\text { Toolbox }\end{array}$ \\
\hline & & eye irritation & 1 & $\begin{array}{l}\text { OECD QSAR } \\
\text { Toolbox }\end{array}$ \\
\hline & & rat oral LD50 & 3 & TEST \\
\hline & eco toxicity & fish acute LC50 & 8 & VEGA, TEST \\
\hline & & $\begin{array}{l}\text { Daphnia magna } \\
\text { LC50 } 48 \mathrm{~h}\end{array}$ & 7 & VEGA, TEST \\
\hline & & $\begin{array}{l}\text { T. pyriformis } \\
\text { IGC50 } 48 \mathrm{~h}\end{array}$ & 4 & TEST \\
\hline M & & $\log K_{\mathrm{oc}}$ & 3 & $\begin{array}{l}\text { VEGA, } \\
\text { EPISUITE }\end{array}$ \\
\hline
\end{tabular}

Decision Making Approaches with MCDA Methods. The obtained human health and environmental hazard parameters were used as 20 assessment criteria within three MCDA strategies: heat mapping, MAUT, and ELECTRE III. These criteria were selected to reflect legislative requirements (e.g., REACH), criteria used in common alternatives assessment frameworks, and availability of in silico tools. For the heat map, the range of each criterion was divided into four intervals, and each interval was color-coded (red, orange, yellow, or green-from hazardous to benign) to aid visual interpretation. Regulatory or proposed thresholds of the assessment criteria were obtained from various sources, including EU legislation, USEPA regulations, GreenScreen 
rules, etc. The details on how the thresholds of the four intervals were determined for each criterion are presented in Section 2 of the SI.

For the MAUT approach, each criterion was scaled from 0 (worst) to 1 (best) based on the average result of all models for that criterion. After the scaling, partial scores for P, B, T, and $M$ properties were calculated by multiplying each criterion relevant to an aspect with the same weight. Final scores were calculated by treating the composite criteria of either PBT, PMT, or PBMT as equally important (SI Table S4).

For ELECTRE III, the calculation was done in a manner consistent with other publications. ${ }^{32,73,74}$ Thresholds were set and pairwise comparisons were conducted on each assessment criterion. Partial scores were calculated for P, B, M, and T (SI Table S5-S8), and final scores were also calculated by treating PBT, PMT, or PBMT equally important (SI Table S9-S11).

\section{RESULTS AND DISCUSSION}

Database of DecaBDE Alternatives. In total, 31 alternatives to decaBDE including polymers and inorganic chemicals have been identified and assessed by various agencies (Table 2, SI Table S1). Among the alternatives, 17

Table 2. Names of Studied Chemicals with Their Abbreviations and Chemical Abstract Service (CAS) Registry Numbers

\begin{tabular}{|c|c|c|}
\hline name & abbreviation $^{a}$ & CAS number \\
\hline decabromodiphenyl ether & decaBDE & $1163-19-5$ \\
\hline decabromodiphenyl ethane & DBDPE & $84852-53-9$ \\
\hline ethylene bis-tetrabromophthalimide & EBTEBPI & $32588-76-4$ \\
\hline $\begin{array}{l}\text { tetrabromobisphenol A bis }(2,3- \\
\text { dibromopropyl) ether }\end{array}$ & TBBPA-BDBPE & $21850-44-2$ \\
\hline tris(tribromophenoxy) triazine & TTBP-TAZ & $25713-60-4$ \\
\hline 1,2-bis(pentabromophenoxy) ethane & $\mathrm{BPBPE}^{b}$ & $61262-53-1$ \\
\hline 2-ethylhexyl tetrabromobenzoate & ЕН-ТВB & $183658-27-7$ \\
\hline bis(2-ethylhexyl) tetrabromophthalate & BEH-TEBP & $26040-51-7$ \\
\hline tetradecabromodiphenoxybenzene & $\begin{array}{l}4^{\prime}- \\
\text { PeBPOBDE208 }\end{array}$ & $58965-66-5$ \\
\hline Bis(tribromophenoxy) ethane & BTBPE & $37853-59-1$ \\
\hline $\begin{array}{l}\text { bis(hexachlorocyclopentadieno) } \\
\text { cyclooctane }\end{array}$ & DP & $13560-89-9$ \\
\hline tris(tribromoneopentyl) phosphate & TTBNPP & $19186-97-1$ \\
\hline triphenyl phosphate & ТPHP & $115-86-6$ \\
\hline resorcinol bis(diphenyl phosphate) & PBDPP & $57583-54-7$ \\
\hline bisphenol A diphenyl phosphate & BPA-BDPP & $5945-33-5$ \\
\hline tris(2-bromoethyl) phosphate & $\mathrm{TBEP}^{b}$ & $27568-90-7$ \\
\hline melamine & $\mathrm{MA}^{b}$ & $108-78-1$ \\
\hline
\end{tabular}

${ }^{a}$ Abbreviations taken from Bergman et al. ${ }^{75}{ }^{b}$ Abbreviations defined by the authors (not covered by Bergman et al. ${ }^{75}$ ).

including decaBDE were defined as suitable for the considered assessment, as they were organic compounds for which the available in silico tools applied in this study could be used. The 17 substances include 10 brominated and 1 chlorinated FR (CFR), five OPFRs (two brominated and three nonhalogenated), and melamine. Their chemical names, abbreviations, CAS numbers, molecular structures, and selected physicochemical properties are listed in Table 2 and SI Table S2.

Structural and Chemical Property Variation. The average molecular weight of the flame retardants was 766 with a large range spanning from 126 for melamine to 1367 for 4'-PeBPOBDE208 (for comparison, decaBDE is 959).
DecaBDE has a very low vapor pressure of $6.3 \times 10^{-10} \mathrm{~Pa}$ at $25{ }^{\circ} \mathrm{C}$, this is in the middle range of the alternative FRs, ranging from $4.9 \times 10^{-18} \mathrm{~Pa}\left(4^{\prime}\right.$-PeBPOBDE208) to $1.3 \times$ $10^{-3} \mathrm{~Pa}$ (TBEP). The estimated octanol-water partition coefficients $\left(\log K_{\mathrm{ow}}\right)$ are ranging from melamine $(-0.4)$, OPFRs (2.3-9.6) to halogenated FRs (7.2-14.2) (decaBDE (10.4)). The chemical variation of the FRs, including decaBDE, was analyzed in more detail using calculated chemical descriptors and PCA, see SI Section 3.

Experimental Data. Experimental data identified in the OECD QSAR Toolbox included 2866 experimental data points (SI Table S12). Despite the large amount of data, a large proportion was only relevant to a few chemicals, and rarely for the same property across different chemicals. For example, 513 data points were collected for melamine and 275 for decaBDE, while no data were found for five of the target FRs (BPBPE, EH-TBB, PBDPP, 4'-PeBPOBDE208, and TBEP). There were 769 data points for eight FRs for repeated dose toxicity for human health hazard assessment, but no data for neurotoxicity. Another issue with these data is they do not allow for systematic comparisons across substances. For example, 843 data points were found for aquatic toxicity of our target FRs, though covering diverse indicators, such as behavior, body size, DNA damage, or lethality. The ECHA database of REACH dossiers was the largest source of OECD data. Additional, more recent data was also obtained directly from REACH dossiers. ${ }^{67}$ Even this additional data were far from sufficient in closing data gaps (SI Section 4 and Table S13). Further, the reliability of data in REACH dossiers has been criticized in general ${ }^{76,77}$ and for flame retardants specifically, ${ }^{56}$ in which the majority of REACH dossiers have been reported as "partly or substantially not compliant" contain significant data gaps and data quality issues. ${ }^{56,77}$ In summary, the collected experimental data is thus not a complete nor suitable source of information for a first tier alternatives assessment.

In Silico Data. The analyzed in silico data are shown in SI Table S14. Among the 20 criteria listed in Table 1, 17 of them (85\%) had assessment results for all 17 chemicals. Among the in silico data, six (1.8\%) data gaps had to be filled in manually for the alternatives assessment, of which four could be filled in by the experimental data from the ECHA database. Readacross was applied to fill in the remaining two data gaps as explained in SI Section 5. The largest number of QSAR models were available for fish and Daphnia magna and acute toxicity (seven and eight, respectively), whereas skin sensitization, skin and eye irritation, and persistence criteria including biodegradation and half-lives for four different environmental compartments had only one model for each criterion. The 20 criteria populated by in silico data cover most of the hazard criteria concerned by REACH ${ }^{2}$ as well as the most well-known alternatives assessment frameworks including U.S. EPA Cleaner Technologies Substitutes Assessment, ${ }^{8}$ BizNGO with GreenScreen, ${ }^{9}$ and U.S. EPA Design for Environment Program. ${ }^{7,78}$ Generally speaking, the quality of in silico data, at large, varies depending on, for example, experimental data used in training the models and their statistical performance ${ }^{56}$ (see SI Section 6 for more details). Because of the identified data gaps in experimental data, the in silico data of the 20 criteria was used for the further decision-making process.

Decision Making Approaches. With data for 20 criteria, it is not trivial to identify a more or less hazardous decaBDE replacement, which emphasizes the need for a good decision 


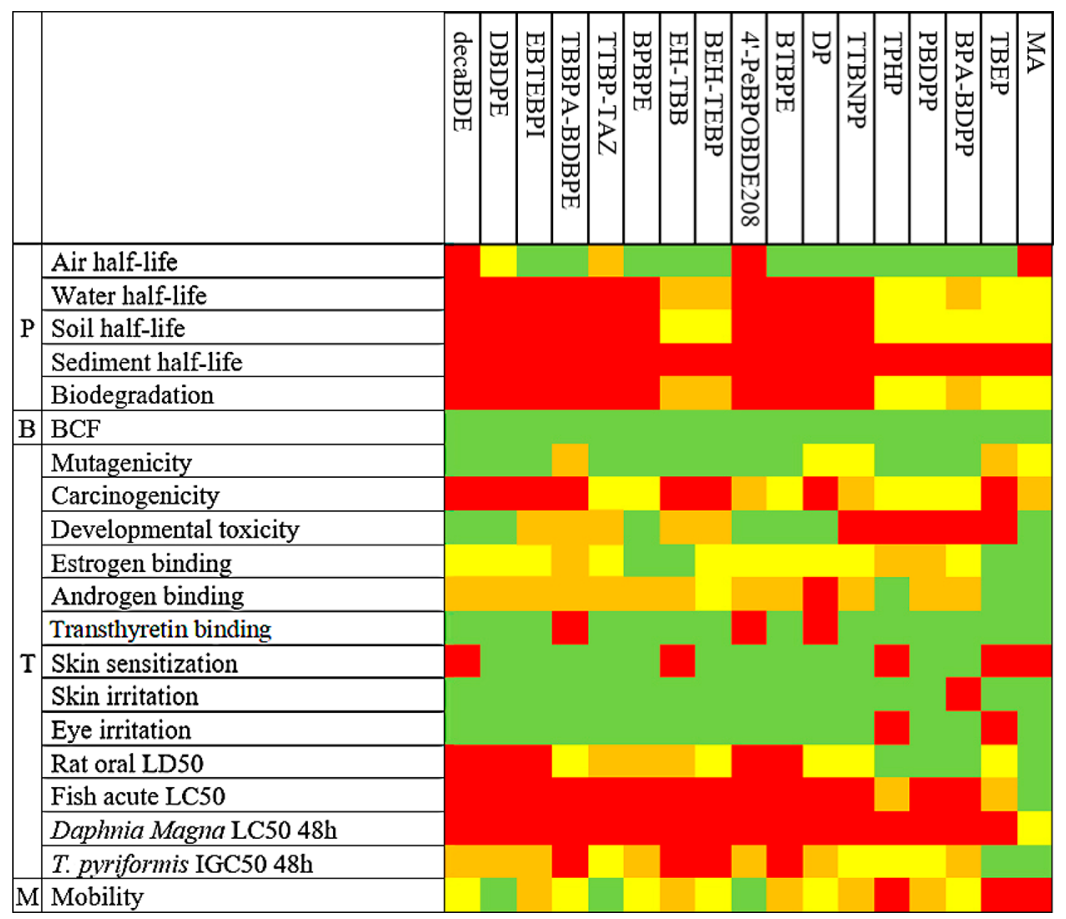

Figure 2. Heat map of the 17 flame retardants where red indicates that a hazard criterion has been met, orange and yellow indicate high and moderate hazard level, and green indicates that the chemical has properties fulfilled a set safe level (SI Section 2). Thresholds for the four categories of each criterion is listed in SI Table S3.

strategy in alternatives assessment processes (SI Figure S10,). Here, three MCDA methods were tested.

Heat Map. The heat map (Figure 2), which color codes the ranges of each criterion, suggests that decaBDE is the most hazardous FR in the database as it has 10 of 20 categories (Table 1) labeled red, that is, classified as hazardous according to regulatory or literature cutoff values (SI Table S1); other substances have nine or fewer categories labeled red. Following this, six out of the other halogenated FRs obtained eight or nine red indicators (DBDPE, EBTEBPI, TBBPA-BDBPE, 4'PeBPOBDE208, BTBPE, and DP), none of which are halogenated OPFRs. Among the five OPFRs, the brominated OPFRs TTBNPP and TBEP had seven red indicators, appearing more hazardous than the three nonhalogenated ones, TPHP, PBDPP, and BPA-BDPP, which had six, four, and five red indicators, respectively. Melamine had among the fewest red indicators, having only four, in addition to one orange, five yellow, and the highest number of green indicators (10). Melamine is often used together with OPFRs, ${ }^{79,80}$ but has also been reported to have good flame retardancy itself. $^{81,82}$ PBDPP (four red, three orange, five yellow, and eight green indicators) appeared to be the best OPFR as well as the second best choice among all studied chemicals. The BFRs that appear as best alternatives are BEH-TEBP (five red, three orange, five yellow, and seven green indicators) and BPABDPP (five red, four orange, four yellow, and seven green indicators). All chemicals achieved at least one red indicator for $\mathrm{P}$ and $\mathrm{T}$, though for $\mathrm{M}$ there was a scatter across all colors. The B property was flagged green for all chemicals, though it is known some of these substances bioaccumulate, such as decaBDE, ${ }^{83,84} \mathrm{DP}^{85}$ and DBDPE. ${ }^{55,56}$ In REACH, the $\mathrm{B}$ parameter is based on the estimated bioconcentration factor (BCF) in fish, with a limit value of 2000 for $\mathrm{B}^{2}$. However, this does not account for other modes of bioaccumulation, for example, in soils or biomagnification through terrestrial food chains. In Europe decaBDE was classified as B because of similarities in fate to very bioaccumulative substances, and because transformation products of decaBDE are bioaccumulative substances. ${ }^{83,84} \mathrm{DP}$ also did not meet the BCF threshold, but has been classified as potential very bioaccumulative and should be handled as one ${ }^{85}$ due to the frequent observations in aquatic biota, terrestrial organisms, and even humans. For DBDPE, this compound is very bioaccumulative, with a measured bioaccumulation factor (log BAF) up to 7.1 , $^{55}$ considering food and diet, which is almost six log units higher than the $\log$ BCF value used in this study. ${ }^{86,89}$ Thus, some flame retardants are clearly bioaccumulative, but their estimated BCF values are below 2000 which may be due to issues with the estimates or alternative uptake mechanisms, which points out the demand for using both experimental data and in silico data for assessing other B related measures like the biomagnification factor (BMF) or bioaccumulation factor (BAF). A previous review also pointed out that laboratory BCF data, which were commonly used for establishing BCF models, tend to be underestimated compared with field BAFs. ${ }^{86}$ Unfortunately, such BAF measurements are lacking for model establishment. ${ }^{86}$

The heat map clearly shows that there is no clear winner among our target FRs, that none of the chemicals fully satisfies all the regulatory criteria (i.e., achieving no red indicators). These results agree well with a previous PBT screening of FRs including 14 substances of those studied here (except TBEP and melamine). ${ }^{36}$ These authors concluded that the 14 FRs were either PB or PT, and three FRs (BPBPE, EH-TBB, and PBDPP) fulfilled their PBT criteria. This is a common situation in alternatives assessment for frameworks with fixed thresholds, such as the USEPA $\mathrm{DfE}^{7}$ and GreenScreen, ${ }^{9}$ that no sustainable choice is available and the demand has become to select the "least worst" choice. This means that the MCDA cannot be elegantly condensed into a "sorting problematic", 32 
for example sorting chemicals into fully acceptable or fully unacceptable classes. Rather, a "ranking problematic" is called for, in which details like the relative half-lives are preserved and considered in conjunction with the other data. In such cases, a heat map has some disadvantages. First, since a different number of criteria are considered for each property, that is, 13 $\mathrm{T}$ criteria, $5 \mathrm{P}$ criteria, and just $1 \mathrm{~B}$ and $1 \mathrm{M}$ criterion, this allows $\mathrm{T}$ to arguably be overemphasized. Second, setting thresholds based on legislation or cutoff values from other alternatives assessment frameworks can make the differences between chemicals become less clear in the heat map for some criteria. For example, the sediment half-lives appear red for all 17 chemicals, that is, these chemicals all qualify for the very persistent criteria of REACH. Therefore, they all get the same color on the heat map despite the variation of almost a factor of 5 across all FRs. ${ }^{7,9}$ Considering the discussion that B should be more than bioconcentration, adding further B criteria, such as bioaccumulation or biomagnification, will also make it more complex and difficult to identify the "least worse" option using a heat map; as the more criteria, the smaller the chance any of the alternatives will be hazard free.

MAUT. As a synthesizing criterion method, MAUT can manage the fact that $\mathrm{P}, \mathrm{B}, \mathrm{M}$, and $\mathrm{T}$ have different numbers of criteria, by assigning weighing factors to all criteria to make $\mathrm{P}$, $\mathrm{B}, \mathrm{T}$, and $\mathrm{M}$ equally important. Since the heat map indicates that using only legislative or literature values to determine cutoff values might not be suitable for our data, a new strategy was developed for MAUT, that for each criterion, input data on chemical hazards were scaled from 0 (worst) to 1 (best) based on the distance between our worst case to an ideal level, or a set worst case to our best case. Details for setting the scaling ranges are further presented in SI Section 7. The final scales for MAUT are listed in Table 3.

Consistent with the heat map, partial scores for the four properties ( $\mathrm{P}, \mathrm{B}, \mathrm{M}$, and $\mathrm{T}$ ) from MAUT show that none of the FRs are good with respect to all properties (SI Figure S11). DecaBDE ranked worst for $\mathrm{P}$ and also had a poor T ranking. The best ranked FR according to the heat map, melamine, performed well on $\mathrm{P}, \mathrm{B}$, and $\mathrm{T}$, but has the worst $\mathrm{M}$ ranking. The worst chemical with respect to $T$ is TBBPA-BDBPE, and the worst with respect to B is BTBPE.

Though MAUT overcomes some of the limitations of using a heat map, by more clearly ranking substances, this method also has its own problems. First, MAUT requires aggregation independence, ${ }^{87}$ which is problematic for diverse chemical hazard criteria, as some criteria may be correlated to similar physicochemical properties. For instance, the BCF and $M$ factors correlate to some extent with $K_{\text {ow }}$ for many substances. Toxicity through baseline narcosis is also directly related with $K_{\text {ow }}$ for several nonpolar organics ${ }^{88}$ including BFRs. ${ }^{56}$ Another example is that half-lives for sediment, soil, and water calculated from EPISUITE are linearly correlated with each other. Second, the MAUT system illustrated here is based on average values and neglects the question of whether averages differ significantly, which may result in erroneous conclusions. One example is illustrated in SI Figure S12 where data from seven different models on acute toxicity (Daphnia magna LC50 $48 \mathrm{~h}$ ) are compared and among the 17 case chemicals, only MA has a value that is significantly different from the others. MAUT therefore needs to be performed alongside a sensitivity analysis to see the robustness of conclusions.

ELECTRE III. ELECTRE III is an example of a synthesizing preference relational system that can use thresholds defined via

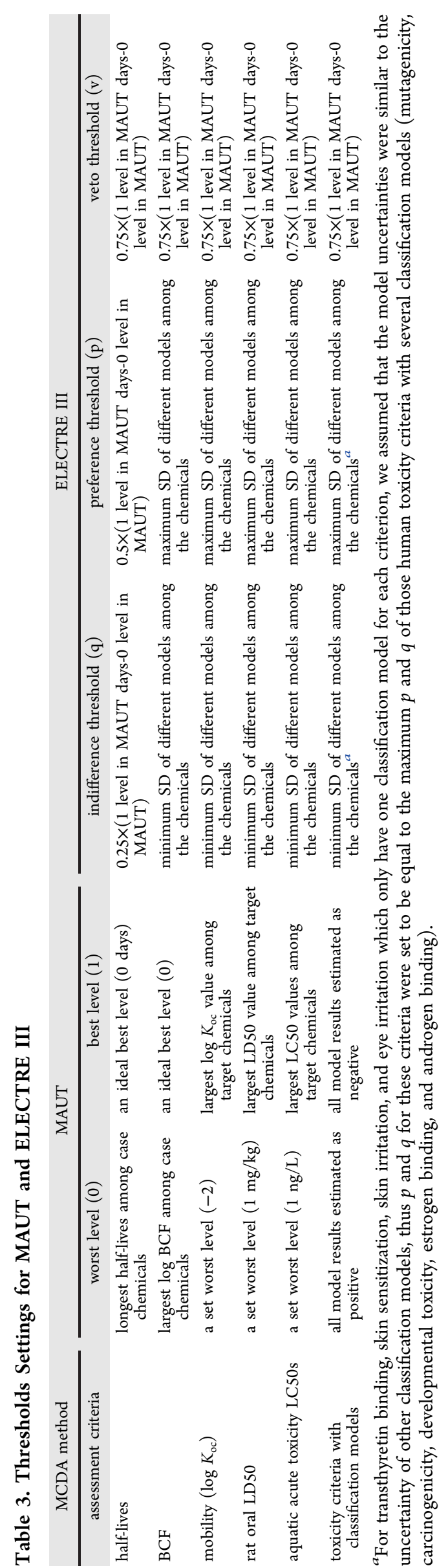




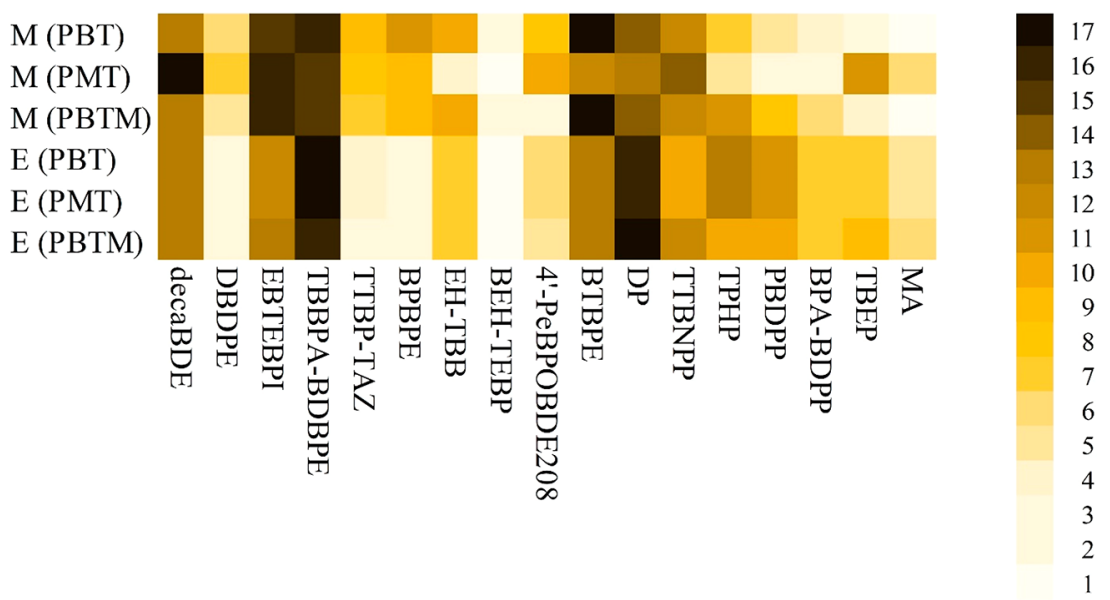

Figure 3. Different final score ranking results of the MAUT (M) and ELECTRE III (E) methods.

consideration of data uncertainties. There are three important thresholds for each criterion in ELECTRE III: indifference thresholds $(q)$, preference thresholds $(p)$, and veto thresholds $(v)$. In practical terms, when the difference between alternatives $\mathrm{A}$ and $\mathrm{B}$ with respect to criterion $j$ is less than $q$, the weight of criterion $j$ is not considered in the comparison between $\mathrm{A}$ and $\mathrm{B}$, and if the difference is larger than $p$, the full weight of criterion $j$ should be awarded to the superior alternative. A sliding scale exists between $p$ and $q$, but if the difference is as large as a defined $v$, the ELECTRE method eliminates the underperforming alternative from contention. $^{34,73}$ In this study, $q$ and $p$ were set based on data uncertainties by considering standard deviation (SD) of different model results for the same criteria for each of the chemicals. Details regarding the settings for $q, p$, and $v$ is shown in Table 3.

The partial scores of $\mathrm{B}$ and $\mathrm{M}$ are identical between ELECTRE III and MAUT, since each property is based on only one criterion (SI Figure S13). With the consideration of data uncertainties, the $\mathrm{P}$ score for several chemicals were indifferent compared with each other by ELECTRE III (for example seven of the chemicals were ranked one and eight were ranked eight). The ranking of $\mathrm{T}$ is generally similar between MAUT and ELECTRE III, but for a few chemicals it differed considerably. For example, TBEP was ranked the second worst (16) by MAUT but average (10) by ELECTRE III.

Final Score Approaches. Figure 3 presents different final score approaches by both MAUT and ELECTRE III, compounding the end points PBT, PMT, and PBMT. The two different MCDA methods generally reach similar ranking (SI Figure S14), where EBPEBPI, TBBPA-BDBPE, BTBPE, and DP were ranked poorly together with decaBDE for all strategies (PBT, PMT, and PBMT) under both methods, indicating potential regrettable substitutions, whereas DBDPE, $\mathrm{BEH}$-TEBP, and melamine are relatively better alternatives. However, these three compounds also have their problems. ${ }^{55} \mathrm{DBDPE}$ is bioaccumulative as discussed above, with reported $\log$ BAF (6.1-7.1) an order of magnitude higher than decaBDE in fish. ${ }^{55,56}$ Another consideration is transformation products. For BEH-TEBP, although it generally ranked best in our assessment, studies have shown that one of its transformation products is more toxic, viz., mono(2-ethyhexyl) tetrabromophthalate (TBMEHP) ${ }^{89}$ TBMEHP was studied in all our models and the results indicate only one extra red flag in the heat map than BEH-TEBP, whereas the ranking in MAUT (PBMT) decreased from second to sixth position. A large range of biotic and abiotic transformation products could theoretically be generated from studied FRs and as an example the OECD QSAR Toolbox generated 12-90 different transformation products for the studied FRs. However, an important consideration is yields of some of these transformation products may be only formed in minor or negligible quantities. But the issue of yields also relates to mass, and therefore, differences in tonnages required across FRs, when used in products for achieving a similar effect for the decaBDE it is replacing. Assessing transformation products, their yields, and tonnage/exposure considerations warrants further development for inclusion in a more quantitative and comprehensive alternatives assessment procedure than presented here. For melamine, it generally appears to be a less toxic compound with no hazardous transformation products, whereas all MCDA methods suggested that it is a potential PM compound. This compound has been heavily used in many applications besides as a flame retardant and thus environmental and human exposure may be a lot higher than other alternatives, which would need further evaluation via quantitative risk assessment. All the five OPFRs included in this study ranked better than decaBDE, but on the other hand, they were not generally ranked better than the BFRs.

The two different MCDA methods yielded also some different results. For example, the PBMT ranking in MAUT for BPBPE is nine, whereas the same approach in ELECTRE III ranked it three. The major reason for the ranking differences besides the fundamental difference between the two MCDA methods is that none of our case chemicals is worse than any other case chemicals for all properties (except for the case of DBDPE, which is no worse than decaBDE for all 17 properties), a situation which facilitates rank reversal. Generally, the inclusion of $\mathrm{M}$ as a hazard property had a low impact on ranking of the studied chemicals except if using MAUT and in particular for OPFRs, where four out of five compounds were ranked worse if applying PBMT as compared with PBT. The compound most affected by the inclusion of $M$ was 4 '-PeBPOBDE208, for which ranking improved from eight to three based on low mobility.

Environmental Implications. Exchanging chemicals in materials and products with safer alternatives can be a tedious 
and costly process; available methodologies require interdisciplinary approaches, broad competences, and lots of data. In silico methodologies can provide a means to fill data gaps and speed up processes. Good decision making requires strategies and methodologies that consider uncertainties in data and the multitude of aspects including environmental, consumer, and occupational hazards; in addition to data on the chemical's product effectiveness, life cycle, and economic factors. Different MCDA methods have their own advantages and disadvantages. Here we assessed a range of alternatives to decaBDE using mainly in silico based data with a focus on environmental and human health hazards. The absence of a fully compliant, clear "winner" was indicated by the heat mapping which instead showed the value of continuing the search for sustainable decaBDE alternatives. Inorganic FRs and polymer FRs were excluded from this study due to their unsuitableness to the applied in silico methodologies but could potentially provide more sustainable options. Alternative approaches including rule-based protocols have been suggested both for inorganics ${ }^{90}$ and polymers, ${ }^{91,92}$ which could be included in future assessments. However, when alternative options are limited, it is not always a question of picking a compliant chemical, but the "least worst" alternative. In this study, we use two MCDA methods (MAUT and ELECTRE III) to achieve this, and were able to incorporate more subtleties in the underlying data. For the identified "less hazardous" chemicals, more detailed hazard assessment should be conducted including their possible transformation products, yield, and other criteria like technical feasibility and tonnage produced. We also noted that inclusion of the $M$ can reduce the risk of underestimating hazards of more hydrophilic compounds (e.g., OPFRs). It is an unfortunate reality that uncertainties for both experimental and in silico data are generally large. In the future, besides the demand for high quality data or models, we recommend that MCDA methods like ELECTRE III be implemented with consideration of not only the regulatory thresholds, but also data uncertainties. Since our approach focused on the hazard criteria, for any possible better alternatives identified, a quantitative risk assessment with a more thorough exposure assessment might need to be carried out, since the emissions and exposures can vary due to different use patterns and physicochemical properties. For flame retardants used in several consumer products, indoor exposure is of particular concern for humans. It also has to be acknowledged that important chemical hazards are overlooked, such as BAF and BMF. In principle, the combination of in silico tools and MCDA methods could be expanded to explore these additional properties; further, the quantitate exposure aspects could be adjusted by considering different use and emission levels. It is unlikely that there will be enough empirical data to compare these diverse considerations; however, the combination of in silico tools and MCDA methods could also be developed for the broader selection of alternative substances and how they ought to be used.

\section{ASSOCIATED CONTENT}

\section{S Supporting Information}

The Supporting Information is available free of charge on the ACS Publications website at DOI: 10.1021/acs.est.8b07163.

Detailed information on the chemical database establishment; threshold settings for heat mapping; chemical variation results analyzed by PCA; data gaps and data comparability issues of experimental data collected from the ECHA database of the REACH dossiers; how the data gaps of in silico data were filled; data quality of the calculated in silico data; data pretreatment and thresholds determination for MAUT and ELECTRE III (PDF) Collected experimental and in silico data; MAUT and ELECTRE III calculation sheets (XLSX)

\section{AUTHOR INFORMATION}

\section{Corresponding Author}

*Phone: +46 90-786 52 66; e-mail: patrik.andersson@umu.se. ORCID $\odot$

Ziye Zheng: 0000-0002-7898-341X

Patrik L. Andersson: 0000-0002-2088-6756

\section{Notes}

The authors declare no competing financial interest.

\section{ACKNOWLEDGMENTS}

This study was financed by a grant from the Swedish Research Council for the Environment, Agricultural Sciences and Spatial Planning (Formas) (942-2015-672).

\section{REFERENCES}

(1) Frank, R. Lautenberg Chemical Safety for the 21st Century Act, H.R. 2576, 114th Congress, Washington, DC, 2016,.

(2) European Commission. Regulation (EC) No 1907/2006 of the European Parliament and of the Council of 18 December 2006 concerning the Registration, Evaluation, Authorisation and Restriction of Chemicals (REACH), establishing a European Chemicals Agency, amending Directive 1999/45/EC and repealing Council Regulation (EEC) No 793/93 and Commission Regulation (EC) No 1488/94 as well as Council Directive 76/769/EEC. Off. J. Eur. Communities: Legis. 2006, L396, 1-849.

(3) Zimmerman, J. B.; Anastas, P. T. Toward substitution with no regrets. Science 2015, 347 (6227), 1198-1199.

(4) Horan, T. S.; Pulcastro, H.; Lawson, C.; Gerona, R.; Martin, S.; Gieske, M. C.; Sartain, C. V.; Hunt, P. A. Replacement Bisphenols Adversely Affect Mouse Gametogenesis with Consequences for Subsequent Generations. Curr. Biol. 2018, 28 (18), 2948-2954.e3.

(5) Arnold, S. M.; Greggs, B.; Goyak, K. O.; Landenberger, B. D.; Mason, A. M.; Howard, B.; Zaleski, R. T. A quantitative screeninglevel approach to incorporate chemical exposure and risk into alternative assessment evaluations. Integr. Environ. Assess. Manage. 2017, 13 (6), 1007-1022.

(6) Dorman, D. C.; Beckman, E. J.; Beak, P.; Cura, J. J.; Fairbrother, A.; Greene, N.; Henry, C.; Holder, H.; Hutchison, J. E.; Paoli, G. M.; Quint, J. B. A Framework to Guide Selection of Chemical Alternatives; National Academies Press: Washington DC, 2014.

(7) Lavoie, E. T.; Heine, L. G.; Holder, H.; Rossi, M. S.; Lee, R. E.; Connor, E. A.; Vrabel, M. A.; DiFiore, D. M.; Davies, C. L. Chemical Alternatives Assessment: Enabling Substitution to Safer Chemicals. Environ. Sci. Technol. 2010, 44 (24), 9244-9249.

(8) Kincaid, L.; Meline, J.; Davis, G. Cleaner Technologies Substitutes Assessment (CTSA) Methodology and Resource Guide; U.S. Environmental Protection Agency: Washington DC, 1996.

(9) Rossi, M., Peele, C., Thorpe, B. BizNGO Chemical Alternatives Assessment Protocol: How to Select Safer Alternatives to Chemicals of Concern to Human Health or to the Environment; The Business-NGO Working Group, 2012; https://www.bizngo.org/static/ee_images/ uploads/resources/BizNGOChemicalAltsAssessmentProtocol_V1.1_ 04 12 12-1.pdf (accessed April 8, 2019).

(10) Geiser, K.; Goldberg, T. Envisioning the future of the interstate chemicals clearinghouse, The Clearinghouse, 2010; http://www. newmoa.org/prevention/webconferences/plancom/IC2_Future.pdf (accessed April 8, 2019). 
(11) Stockholm Convention on Persistent Organic Pollutants Review Committee, Report of the persistent organic pollutants review committee on the work of its first meeting, UNEP/POPS/POPRC.1/10. Geneva, 7-11, November 2005.

(12) Gilbert, Y.; Pessala, P.; Aho, J.; Lehti, R.; Vehviläinen, I.; Hjelt, M. Minimising Chemical Risk to Workers' Health and Safety through Substitution; Publications Office of the European Union: Luxembourg, 2012.

(13) Quinn, M. M.; Fuller, T. P.; Bello, A.; Galligan, C. J. Pollution prevention-occupational safety and health in hospitals: alternatives and interventions. J. Occup. Environ. Hyg. 2006, 3 (4), 182-193.

(14) Rosenberg, B. J.; Barbeau, E. M.; Moure-Eraso, R.; Levenstein, C. The work environment impact assessment: A methodologic framework for evaluating health-based interventions. Am. J. Ind. Med. 2001, 39 (2), 218-226.

(15) Jacobs, M. M.; Malloy, T. F.; Tickner, J. A.; Edwards, S. Alternatives assessment frameworks: research needs for the informed substitution of hazardous chemicals. Environ. Health Perspect. 2016, 124 (3), 265.

(16) Berger, U.; Ost, N.; Sättler, D.; Schliebner, I.; Kühne, R.; Schüürmann, G.; Neumann, M.; Reemtsma, T. Assessment of persistence, mobility and toxicity (PMT) of $167 \mathrm{REACH}$ registered substances, Report (UBA-FB) 002595, 2018; https://www. umweltbundesamt.de/sites/default/files/medien/1410/ publikationen/2018-02-12_texte_09-2018_pmt-of-167-reachsubstances v3.pdf (accessed April 8, 2019).

(17) Kalberlah, F.; Oltmanns, J.; Schwarz, M.; Guidance for Assessing Persistence, Mobility and Toxicity of Chemicals Registered under Reach and Their Metabolites to Protect Raw Water Destined for Drinking Water: A Practical Guide; Forschungs- und Beratungsinstitut Gefahrstoffe GmbH (FoBiG), 2014.

(18) Neumann, M.; Schliebner, I. Protecting the Sources of Our Drinking Water-A Revised Proposal for Implementing Criteria and an Assessment Procedure to Identify Persistent, Mobile and toxic (PMT) and Very Persistent, Very Mobile ( $v P v M)$ Substances Registered Under REACH; German Environment Agency, 2017; ISSN 0013-936X.

(19) Arp, H.; Brown, T.; Berger, U.; Hale, S. Ranking REACH registered neutral, ionizable and ionic organic chemicals based on their aquatic persistency and mobility. Environ. Sci. Process. Impacts 2017, 19 (7), 939-955.

(20) Schulze, S.; Sättler, D.; Neumann, M.; Arp, H. P. H.; Reemtsma, T.; Berger, U. Using REACH registration data to rank the environmental emission potential of persistent and mobile organic chemicals. Sci. Total Environ. 2018, 625, 1122-1128.

(21) Patlewicz, G.; Roberts, D. W.; Aptula, A.; Blackburn, K.; Hubesch, B. Workshop: use of "read-across" for chemical safety assessment under REACH. Regul. Toxicol. Pharmacol. 2013, 65 (2), 226-228.

(22) Gramatica, P. Principles of QSAR models validation: internal and external. QSAR Comb. Sci. 2007, 26 (5), 694-701.

(23) OECD. OECD Principles for the Validation, for Regulatory Purposes, of (Quantitative) Structure-Activity Relationship Models. http://www.oecd.org/chemicalsafety/risk-assessment/37849783.pdf (accessed April 8, 2019).

(24) Ishizaka, A.; Nemery, P. Multi-criteria decision analysis: methods and software. John Wiley \& Sons: West Sussex, 2013.

(25) Cinelli, M.; Coles, S. R.; Kirwan, K. Analysis of the potentials of multi criteria decision analysis methods to conduct sustainability assessment. Ecol. Indic. 2014, 46, 138-148.

(26) Janssen, R. On the use of multi-criteria analysis in environmental impact assessment in The Netherlands. J. Mult. Crit. Anal. 2001, 10 (2), 101-109.

(27) Hermann, B.; Kroeze, C.; Jawjit, W. Assessing environmental performance by combining life cycle assessment, multi-criteria analysis and environmental performance indicators. J. Cleaner Prod. 2007, 15 (18), 1787-1796.

(28) Malloy, T. F.; Sinsheimer, P. J.; Blake, A.; Linkov, I. Use of multi-criteria decision analysis in regulatory alternatives analysis: A case study of lead free solder. Integr. Environ. Assess. Manage. 2013, 9 (4), 652-664.

(29) Linkov, I.; Satterstrom, F. K.; Steevens, J.; Ferguson, E.; Pleus, R. C. Multi-criteria decision analysis and environmental risk assessment for nanomaterials. J. Nanopart. Res. 2007, 9 (4), 543-554.

(30) Linkov, I.; Satterstrom, F. K.; Kiker, G.; Batchelor, C.; Bridges, T.; Ferguson, E. From comparative risk assessment to multi-criteria decision analysis and adaptive management: Recent developments and applications. Environ. Int. 2006, 32 (8), 1072-1093.

(31) Kiker, G. A.; Bridges, T. S.; Varghese, A.; Seager, T. P.; Linkov, I. Application of multicriteria decision analysis in environmental decision making. Integr. Environ. Assess. Manage. 2005, 1 (2), 95-108.

(32) Rowley, H. V.; Peters, G. M.; Lundie, S.; Moore, S. J. Aggregating sustainability indicators: beyond the weighted sum. J. Environ. Manage. 2012, 111, 24-33.

(33) Von Winterfeldt, D.; Fischer, G. W. Multi-attribute utility theory: Models and assessment procedures. In Utility, Probability, And Human Decision Making; Wendt, D., Vlek, C. A.; D. Reidel Publishing Company: Dordrecht, 1975; pp 47-85.

(34) Roy, B. ELECTRE III: Un algorithme de classement fondé sur une représentation floue des préférences en présence de critères multiples. Cahiers du CERO 1978, 20 (1), 3-24.

(35) Birnbaum, L. S.; Staskal, D. F. Brominated flame retardants: cause for concern? Environ. Health Perspect. 2004, 112 (1), 9.

(36) Gramatica, P.; Cassani, S.; Sangion, A. Are some "safer alternatives" hazardous as PBTs? The case study of new flame retardants. J. Hazard. Mater. 2016, 306, 237-246.

(37) Shaw, S. Halogenated flame retardants: do the fire safety benefits justify the risks? Rev. Environ. Health 2010, 25 (4), 261-306.

(38) Robrock, K. R.; Korytár, P.; Alvarez-Cohen, L. Pathways for the anaerobic microbial debromination of polybrominated diphenyl ethers. Environ. Sci. Technol. 2008, 42 (8), 2845-2852.

(39) Boon, J. P.; Lewis, W. E.; Tjoen-A-Choy, M. R.; Allchin, C. R.; Law, R. J.; de Boer, J.; ten Hallers-Tjabbes, C. C.; Zegers, B. N. Levels of polybrominated diphenyl ether (PBDE) flame retardants in animals representing different trophic levels of the North Sea food web. Environ. Sci. Technol. 2002, 36 (19), 4025-4032.

(40) Darnerud, P. O. Toxic effects of brominated flame retardants in man and in wildlife. Environ. Int. 2003, 29 (6), 841-853.

(41) Herbstman, J. B.; Sjödin, A.; Kurzon, M.; Lederman, S. A.; Jones, R. S.; Rauh, V.; Needham, L. L.; Tang, D.; Niedzwiecki, M.; Wang, R. Y. Prenatal exposure to PBDEs and neurodevelopment. Environ. Health Perspect. 2010, 118 (5), 712.

(42) Schreiber, T.; Gassmann, K.; Götz, C.; Hübenthal, U.; Moors, M.; Krause, G.; Merk, H. F.; Nguyen, N.-H.; Scanlan, T. S.; Abel, J. Polybrominated diphenyl ethers induce developmental neurotoxicity in a human in vitro model: evidence for endocrine disruption. Environ. Health Perspect. 2010, 118 (4), 572.

(43) Chao, H.-R.; Wang, S.-L.; Lee, W.-J.; Wang, Y.-F.; Päpke, O. Levels of polybrominated diphenyl ethers (PBDEs) in breast milk from central Taiwan and their relation to infant birth outcome and maternal menstruation effects. Environ. Int. 2007, 33 (2), 239-245.

(44) Türk, H. A. Joined Cases C-14/06 \& C-295/06, European Parliament and Denmark v. Commission, judgment of the Court (Grand Chamber) of 1 April 2008. Common Market Law Review 2009, 46 (4), 1293-1303.

(45) Lassen, C.; Havelund, S.; Leisewitz, A.; Maxson, P. DecaBDE and Alternatives in Electrical and Electronic Equipment; Danish Ministry of the Environment: Copenhagen, Denmark, 2006.

(46) Pakalin, S.; Cole, T.; Steinkellner, J.; Nicolas, R.; Tissier, C.; Munn, S.; Eisenreich, S. Review on Production Processes of Decabromodiphenyl Ether (decaBDE) Used in Polymeric Applications in Electrical and Electronic Equipment, And Assessment of the Availability of Potential Alternatives to decaBDE; European Commission, Directorate General Joint Research Center, European Chemicals Bureau, 2007.

(47) All POPs listed in the Stockholm Convention; United Nations Environment Programme, 2017. 
(48) DecaBDE Phase-out Initiative; U.S. Environmental Protection Agency, 2010.

(49) Schreder, E., Peele, C., Uding, N. TV Reality: Toxic Flame Retardants in TVs", Toxic-Free Future and Clean Production Action, 2017; https://toxicfreefuture.org/science/research/flame-retardantstvs/ (accessed April 8, 2019).

(50) Betts, K. Glut of data on "new" flame retardant documents its presence all over the world. Environ. Sci. Technol. 2009, 43 (2), 236237.

(51) Ricklund, N.; Kierkegaard, A.; McLachlan, M. S. Levels and Potential Sources of Decabromodiphenyl Ethane (DBDPE) and Decabromodiphenyl Ether (DecaBDE) in Lake and Marine Sediments in Sweden. Environ. Sci. Technol. 2010, 44 (6), 1987-1991.

(52) Barón, E.; Santín, G.; Eljarrat, E.; Barceló, D. Occurrence of classic and emerging halogenated flame retardants in sediment and sludge from Ebro and Llobregat river basins (Spain). J. Hazard. Mater. 2014, 265, 288-295.

(53) Stapleton, H. M.; Allen, J. G.; Kelly, S. M.; Konstantinov, A.; Klosterhaus, S.; Watkins, D.; McClean, M. D.; Webster, T. F. Alternate and New Brominated Flame Retardants Detected in U.S. House Dust. Environ. Sci. Technol. 2008, 42 (18), 6910-6916.

(54) An Alternatives Assessment For the Flame Retardant Decabromodiphenyl Ether (DecaBDE); U.S. Environmental Protection Agency, 2014.

(55) He, M.-J.; Luo, X.-J.; Chen, M.-Y.; Sun, Y.-X.; Chen, S.-J.; Mai, B.-X. Bioaccumulation of polybrominated diphenyl ethers and decabromodiphenyl ethane in fish from a river system in a highly industrialized area, South China. Sci. Total Environ. 2012, 419, 109115.

(56) Stieger, G.; Scheringer, M.; Ng, C. A.; Hungerbühler, K. Assessing the persistence, bioaccumulation potential and toxicity of brominated flame retardants: Data availability and quality for 36 alternative brominated flame retardants. Chemosphere 2014, 116, $118-123$.

(57) Wei, G.-L.; Li, D.-Q.; Zhuo, M.-N.; Liao, Y.-S.; Xie, Z.-Y.; Guo, T.-L.; Li, J.-J.; Zhang, S.-Y.; Liang, Z.-Q. Organophosphorus flame retardants and plasticizers: sources, occurrence, toxicity and human exposure. Environ. Pollut. 2015, 196, 29-46.

(58) Sun, L.; Xu, W.; Peng, T.; Chen, H.; Ren, L.; Tan, H.; Xiao, D.; Qian, H.; Fu, Z. Developmental exposure of zebrafish larvae to organophosphate flame retardants causes neurotoxicity. Neurotoxicol. Teratol. 2016, 55, 16-22.

(59) Hendriks, H. S.; Westerink, R. H. Neurotoxicity and risk assessment of brominated and alternative flame retardants. Neurotoxicol. Teratol. 2015, 52, 248-269.

(60) Brown, V. J. Why is it so difficult to choose safer alternatives for hazardous chemicals? Environ. Health Perspect. 2012, 120 (7), a280.

(61) Chen, D.; Hale, R. C.; Letcher, R. J. Photochemical and microbial transformation of emerging flame retardants: Cause for concern? Environ. Toxicol. Chem. 2015, 34 (4), 687-699.

(62) Rännar, S.; Andersson, P. L. A novel approach using hierarchical clustering to select industrial chemicals for environmental impact assessment. J. Chem. Inf. Model. 2010, 50 (1), 30-36.

(63) Molecular Operating Environment (MOE), 2015.1001; Chemical Computing Group Inc.: Montreal, QC, Canada, 2015.

(64) Estimation Programs Interface Suite for Microsoft ${ }^{\circledR}$ Windows, v 4.11; U.S. Environmental Protection Agency: Washington, DC, 2012.

(65) Benfenati, E.; Manganaro, A.; Gini, G. C. VEGA-QSAR: AI Inside a Platform for Predictive Toxicology. In Proceedings of Workshop PAI; Turin Italy, 2013.

(66) Dimitrov, S.; Diderich, R.; Sobanski, T.; Pavlov, T.; Chankov, G.; Chapkanov, A.; Karakolev, Y.; Temelkov, S.; Vasilev, R.; Gerova, K. QSAR Toolbox-Workflow and major functionalities. SAR QSAR Environ. Res. 2016, 27 (3), 203-219.

(67) ECHA Registered substances of the REACH registration dossiers; https://echa.europa.eu/information-on-chemicals/ registered-substances (accessed April 8, 2019).

(68) Martin, T. Toxicity Estimation Software Tool (TEST); U.S, Environmental Protection Agency: Washington D.C., 2016.
(69) Mansouri, K.; Abdelaziz, A.; Rybacka, A.; Roncaglioni, A.; Tropsha, A.; Varnek, A.; Zakharov, A.; Worth, A.; Richard, A. M.; Grulke, C. M. CERAPP: Collaborative estrogen receptor activity prediction project. Environ. Health Perspect. 2016, 124 (7), 1023.

(70) Mansouri, K.; Grulke, C. M.; Judson, R. S.; Williams, A. J. Virtual Screening of Chemicals for Endocrine Disrupting Activity through CERAPP and CoMPARA Projects. In ACS Meeting, New Orleans, 2018.

(71) Mansouri, K.; Kleinstreuer, N.; Grulke, C. M.; Shah, I.; Williams, A. J.; Judson, R. Virtual Screening of Chemicals for Endocrine Disrupting Activity: Case Studies of the Estrogen and Androgen Receptors. In SOT Meeting, San Antonio, 2018.

(72) Sushko, I.; Novotarskyi, S.; Körner, R.; Pandey, A. K.; Rupp, M.; Teetz, W.; Brandmaier, S.; Abdelaziz, A.; Prokopenko, V. V.; Tanchuk, V. Y.; Todeschini, R.; Varnek, A.; Marcou, G.; Ertl, P.; Potemkin, V.; Grishina, M.; Gasteiger, J.; Schwab, C.; Baskin, I. I.; Palyulin, V. A.; Radchenko, E. V.; Welsh, W. J.; Kholodovych, V.; Chekmarev, D.; Cherkasov, A.; Aires-de-Sousa, J.; Zhang, Q.-Y.; Bender, A.; Nigsch, F.; Patiny, L.; Williams, A.; Tkachenko, V.; Tetko, I. V. Online chemical modeling environment (OCHEM): web platform for data storage, model development and publishing of chemical information. J. Comput.-Aided Mol. Des. 2011, 25 (6), 533554

(73) El-Zein, A.; Tonmoy, F. N. Assessment of vulnerability to climate change using a multi-criteria outranking approach with application to heat stress in Sydney. Ecol. Indic. 2015, 48, 207-217.

(74) Figueira, J.; Greco, S.; Ehrgott, M. Multiple Criteria Decision Analysis: State of the Art, International Series in Operations Research Management Science; Springer Verlag: Boston, 2005; Vol. 78.

(75) Bergman, Å.; Rydén, A.; Law, R. J.; de Boer, J.; Covaci, A.; Alaee, M.; Birnbaum, L.; Petreas, M.; Rose, M.; Sakai, S. A novel abbreviation standard for organobromine, organochlorine and organophosphorus flame retardants and some characteristics of the chemicals. Environ. Int. 2012, 49, 57-82.

(76) Ylä-Mononen, L. ECHA's New Strategy to Ensure Data Quality in REACH Registrations; https://www.bfr.bund.de/cm/349/echasnew-strategy-to-ensure-data-quality-in-reach-registrations.pdf (accessed April 8, 2019).

(77) REACH data quality comes under renewed fire; https:// chemicalwatch.com/57000/reach-data-quality-comes-under-renewedfire (accessed April 8, 2019).

(78) USEPA Design for the Environment Alternatives Assessments; https://www.epa.gov/saferchoice/design-environment-alternativesassessments (accessed April 8, 2019).

(79) Thirumal, M.; Khastgir, D.; Nando, G.; Naik, Y.; Singha, N. K. Halogen-free flame retardant PUF: effect of melamine compounds on mechanical, thermal and flame retardant properties. Polym. Degrad. Stab. 2010, 95 (6), 1138-1145.

(80) Xu, D.; Lu, H.; Huang, Q.; Deng, B.; Li, L. Flame-retardant effect and mechanism of melamine phosphate on silicone thermoplastic elastomer. RSC Adv. 2018, 8 (9), 5034-5041.

(81) Jenkins, S. Ashford's Dictionary of Industrial Chemicals. Chem. Eng. 2011, 118 (5), 8-9.

(82) Horacek, H.; Grabner, W. In Nitrogen Based Flame Retardants for Nitrogen Containing Polymers, Makromolekulare Chemie. Macromolecular Symposia, 1993; Wiley Online Library: 1993; pp 271-276.

(83) Pakalin, S.; Cole, T.; Steinkellner, J.; Nicolas, R.; Tissier, C.; Munn, S.; Eisenreich, S. Review on Production Processes of Decabromodiphenyl Ether (decaBDE) Used in Polymeric Applications in Electrical and Electronic Equipment, And Assessment of the Availability of Potential Alternatives to decaBDE; European Chemicals Bureau, Institute of Health and Consumer Protection, Joint Research Centre, European Commission, 2007; Vol. EUR 22693 EN.

(84) ECHA Registered substances of the REACH registration dossiers, Bis(pentabromophenyl) ether, PBT assessment; https:// echa.europa.eu/registration-dossier/-/registered-dossier/14217/2/3 (accessed April 8, 2019).

(85) ECHA Registered substances of the REACH registration dossiers, $1,6,7,8,9,14,15,16,17,17,18,18$-dodecachloropentacyclo- 
[12.2.1.16,9.02,13.05,10] octadeca-7,15-diene, PBT assessment; https://echa.europa.eu/registration-dossier/-/registered-dossier/ 11906/2/3 (accessed April 8, 2019).

(86) Arnot, J. A.; Gobas, F. A. A review of bioconcentration factor (BCF) and bioaccumulation factor (BAF) assessments for organic chemicals in aquatic organisms. Environ. Rev. 2006, 14 (4), 257-297.

(87) Clemen, R. T.; Reilly, T. Making Hard Decisions with DecisionTools; Cengage Learning, 2013.

(88) Strempel, S.; Scheringer, M.; Ng, C. A.; Hungerbühler, K. Screening for PBT chemicals among the "existing" and "new" chemicals of the EU. Environ. Sci. Technol. 2012, 46 (11), 5680-5687. (89) Springer, C.; Dere, E.; Hall, S. J.; McDonnell, E. V.; Roberts, S. C.; Butt, C. M.; Stapleton, H. M.; Watkins, D. J.; McClean, M. D.; Webster, T. F. Rodent thyroid, liver, and fetal testis toxicity of the monoester metabolite of bis-(2-ethylhexyl) tetrabromophthalate (TBPH), a novel brominated flame retardant present in indoor dust. Environ. Health Perspect. 2012, 120 (12), 1711-1719.

(90) Verougstraete, V. Risk Management of Complex Inorganic Materials: A Practical Guide; Academic Press: London, 2017.

(91) U.S. Environmental Protection Agency, "Interpretive Assistance Document for Assessment of Polymers", 2013; https://www.epa.gov/ sites / production/files/2015-05/documents/06-iad_polymers june2013.pdf (accessed April 8, 2019).

(92) Australian Gorvernment, Department of Health. Polymer assessment methodology; https://www.nicnas.gov.au/chemicalinformation/imap-assessments/how-chemicals-are-assessed/polymerassessment-methodology (accessed April 8, 2019). 